\title{
Incidence of cancer among vinyl chloride and polyvinyl chloride workers: further evidence for an association with malignant melanoma
}

\author{
S STORETVEDT HELDAAS, ${ }^{1}$ A A ANDERSEN, ${ }^{2}$ S LANGÅRD ${ }^{3}$
}

From the Health Department/Research Center, ${ }^{1}$ Norsk Hydro A/S, Porsgrunn Fabrikker, 3900 Porsgrunn, the Cancer Registry of Norway, ${ }^{2}$ Montebello, Oslo 3, and Telemark Sentralsjukehus, ${ }^{3}$ Department of Occupational Medicine, 3900 Porsgrunn, Norway

In a previous report ${ }^{1}$ we presented results of a mortality study in a cohort of 454 male workers producing vinyl chloride and polyvinyl chloride which gave support to the observations from animal studies ${ }^{2}$ that vinyl chloride (VCM) may act as a multicarcinogen in man. We report here our finding of two new cases of malignant melanoma of the skin in the extended follow up period $1980-4$ versus $0 \cdot 3$ expected, giving six cases versus $1 \cdot 1$ expected overall. Salmon discussed the importance of considering that less specific tumours might also be induced by exposure to VCM, and that high background incidences of such tumours make it difficult to show an increased incidence. ${ }^{3} \mathrm{He}$ found it difficult to dismiss the excess of malignant melanoma in the study population as being the result of confounding factors, owing to the lower background incidences and the fact that the confounding variables (race, sunlight exposure) are more connected with geography than with personal habits, and therefore less likely to vary between control and exposed populations. Salmon also suggested that exposure to ethylene dichloride should be taken into consideration in our study population since it had been used in the process on site, ${ }^{3}$ and he suggested that our data should be reviewed with exposure to ethylene dichloride in mind. Since there was an increase in production and in the number of employees during the work period in which members were recruited to the cohort, the observation period was short for some of the members. ${ }^{1}$

Associations between occupational exposure factors and malignant melanoma of the skin have been suggested by some authors. In a study based on a proportionate mortality analysis Thomas and Decoufle found increased mortality of malignant melanoma among white male pharmaceutical production workers. ${ }^{4}$ Alderson and Rushton found

Accepted 8 July 1986 excess deaths from malignant melanoma among oido refinery workers. ${ }^{5}$ Beral et al showed that individuals with exposure to fluorescent lights at work had an. increased risk of developing malignant melanoma, whereas Rigel et al found no such association. Wright et al reported exposure to organic chemicals and increased risk of developing malignant melaeo noma. ${ }^{8}$ Vågerö et al found that work environments in the telecommunication industry where soldering was practised were associated with excess risk of maligs nant melanoma. ${ }^{9}$ In a register based study wherē occupational units were classified in terms of the्๊ probable amount of soldering work Sorahan et aA found no such association. ${ }^{10}$

Table 1 Broad categories of work indicating exposure levels by follow up period: observed $(O)$ and expected $(E)$ cases of colon cancer (ICD 153), bronchial cancer (ICD 162/163), and malignant melanoma of the skin (ICD 190)

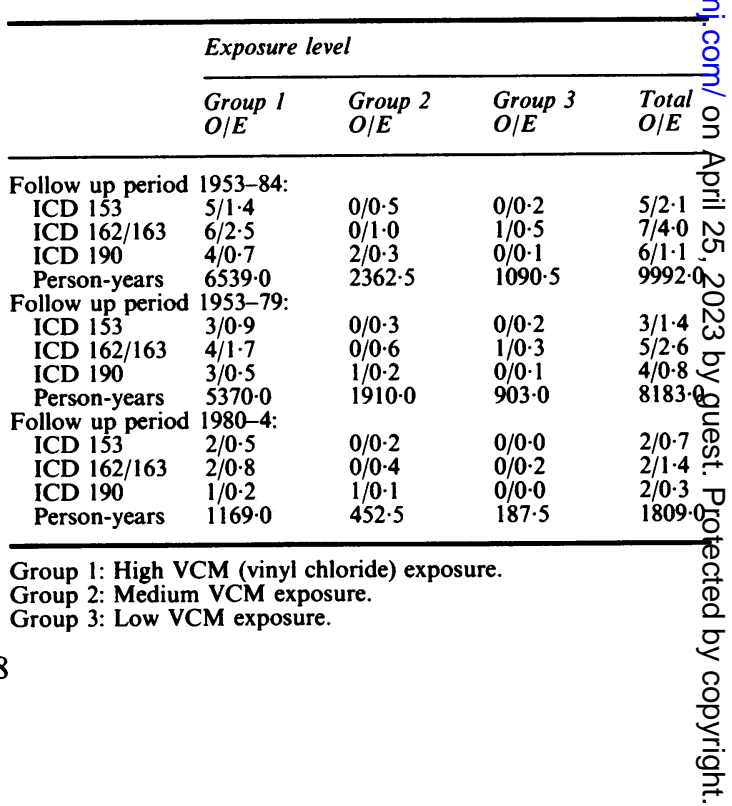


Table 2 Observed $(O)$ and expected $(E)$ cases of cancer (all sites), colon cancer (ICD 153), bronchial cancer (ICD 162/163), and malignant melanoma of the skin (ICD 190) in workers employed between 1950 and 1964 stratified by years from first employment

\begin{tabular}{|c|c|c|c|c|c|c|c|c|c|c|c|c|c|}
\hline \multirow{2}{*}{$\begin{array}{l}\text { Years from } \\
\text { first } \\
\text { employment }\end{array}$} & \multicolumn{3}{|c|}{ All cancers } & \multicolumn{3}{|c|}{$I C D \quad 153$} & \multicolumn{3}{|c|}{$I C D I 62 / 163$} & \multicolumn{3}{|c|}{$I C D I 90$} & \multirow{2}{*}{$\begin{array}{l}\text { Person-years } \\
1953-84\end{array}$} \\
\hline & $O$ & $E$ & $O / E$ & $O$ & $E$ & $O / E$ & $O$ & $E$ & $O / E$ & $O$ & $E$ & $O / E$ & \\
\hline $\begin{array}{c}0-9 \\
10-19 \\
\geqslant 20\end{array}$ & $\begin{array}{r}5 \\
13 \\
13\end{array}$ & $\begin{array}{r}3 \cdot 6 \\
8 \cdot 7 \\
12 \cdot 6\end{array}$ & $\begin{array}{l}1.4 \\
1.5 \\
1.0\end{array}$ & $\begin{array}{l}0 \\
3 \\
0\end{array}$ & $\begin{array}{l}0.2 \\
0.6 \\
1 \cdot 1\end{array}$ & $\frac{5}{-}$ & $\begin{array}{l}\mathbf{0} \\
\mathbf{3} \\
\mathbf{3}\end{array}$ & $\begin{array}{l}0.4 \\
1.2 \\
1.9\end{array}$ & $\begin{array}{l}\overline{2.5} \\
1.6\end{array}$ & $\begin{array}{l}2 \\
2 \\
2\end{array}$ & $\begin{array}{l}0 \cdot 1 \\
0.4 \\
0.4\end{array}$ & $\begin{array}{r}20.0 \\
5.0 \\
5.0\end{array}$ & $\begin{array}{l}3110 \cdot 0 \\
3067 \cdot 0 \\
2187 \cdot 5\end{array}$ \\
\hline Total & 31 & $24 \cdot 0$ & 1.2 & 3 & 1.9 & 1.6 & 6 & $3 \cdot 5$ & 1.7 & 6 & 0.9 & $6 \cdot 7$ & $8364 \cdot 5$ \\
\hline
\end{tabular}

\section{Materials and methods}

The description of the study plant, the population, the estimation of exposure, job classification, and the method of follow up were essentially the same as in the study conducted in $1979 .{ }^{1}$ When reviewing data about members of the cohort, however, it could be shown that some of them had been accounted for more than once in the first investigation due to different exposure categorisation. This was not the case for the patients with cancer, but since the study was based on a comparison of observed and expected values from calculations on person-years, the estimated expected values in the first report were slightly too high. The study population in our first report consisted of 454 male workers and in the present investigation it was reduced to 430 male workers.

\section{Results}

A review of the updated results is presented in table 1. Nine different exposure categories have been combined into three groups reflecting high, medium, and low exposure to VCM. Table 1 also presents the observed and expected numbers for those malignant neoplasms that seem to be of interest. For comparison, the follow up periods 1953-84, 1953-79, and 1980-4 are presented separately. The increased incidence of cancer of the colon, bronchial cancer, and malignant melanoma of the skin-as shown in the previous report ${ }^{1}$ - was confirmed, and was accounted for by the high exposure group. No new cases of liver angiosarcoma appeared in the extended follow up period.

Six malignant melanomas of the skin were observed in the whole study population versus $1 \cdot 1$ expected (table 1). Two new cases appeared in the extended follow up period versus $\mathbf{0 . 3}$ expected. In addition we are aware of one case of incipient malignant melanoma diagnosed in 1977 which was recruited from the medium exposure group. This case has not been included in the table. The tumours were located as follows: three on the trunk, two in the face-neck area, and one on the foot. The incipient malignant mela- noma was located on the trunk. The mean time between first exposure and the time of diagnosis for the seven cases occurring during the follow up period was 17.4 years (range 2-33). Seven cases of lung cancer were found in the study population versus 4.0 expected and two new cases versus 1.4 expected appeared in the extended follow up period. Six of the seven cases were recruited from the high exposure group (table 1). Five cases of colonic cancers were observed versus $2 \cdot 1$ expected. Two new cases versus 0.7 expected occurred in the extended follow up period.

Table 2 presents the results stratified by year since first exposure in those workers who were employed between 1950 and 1964 when the level of exposure to VCM must have been high. ${ }^{1}$ For malignant melanoma there is a difference in the rate ratio between the follow up periods, with highest incidence for the shortest follow up period. For lung cancer, however, there is no apparent difference in the rate ratio between the observation periods.

\section{Discussion}

The excess incidence of malignant melanoma of the skin, lung cancer, and colonic cancer found in the previous study ${ }^{1}$ was also seen in the present follow up study. The presented results also seem to support the view that VCM acts as a multicarcinogen in man, which is in accordance with observations from animal studies. $^{2}$ Salmon suggested that exposure to ethylene dichloride should be considered as a possible causal chemical in our study population as it had been used in the process on site. $^{3}$ The cracking of EDC to VCM, however, was introduced in 1967 and discontinued in 1971 and exposure to EDC could be documented in only one of the colonic cancers, but this worker had had only one year of exposure to EDC and VCM and he had also been exposed to asbestos.

We discussed the increased risk of lung cancer and colonic cancer in our first investigation, ${ }^{1}$ and we have no additional comments. From table 2 it may be deduced that two of the workers in which colonic cancer developed started to work in 1968 and 1969 
respectively. This weakened the suggested association to exposure to VCM, since the exposure to VCM was lower ${ }^{1}$ and the latent period was short. As discussed above there is no evidence that exposure to EDC could explain the findings.

The extended observation period has confirmed the results from the first investigation, which suggested association between exposure to VCM and malignant melanoma of the skin. The additional cases even seem to strengthen the association between exposure to VCM and the development of malignant melanomas. Only the incipient case was diagnosed by the company physician. Therefore, it seems unlikely that the presence of an occupational health service has influenced the results. The incidence of cutaneous malignant melanoma is said to be increasing in all parts of the world where records are kept. ${ }^{11}$ The reason for the rising incidence has still not been fully understood. Many authors have concluded that the association between exposure to ultraviolet light (or sun) and the development of malignant melanoma of the skin was complex ${ }^{1112}$ or indirect. ${ }^{13}$ Unlike patients with skin cancers such as squamous and basal cell carcinoma, the patient with melanoma was not an elderly individual with a high total lifetime exposure to sun like patients with cancers of the skin such as squamous and basal cell carcinoma. ${ }^{13}$ Sober and Fitzpatrick discussed genetic and environmental factors and the induction of malignant melanoma. ${ }^{14}$ Environmental chemicals such as tear gas ( $\alpha$-chloroacetophenone) and polychlorinated biphenyls (PCBs) were suggested as possible causal agents. Hilt et al posed the question as to whether occupational exposure could contribute to the development of malignant melanoma of the skin and suggested that epidemiological studies limited to patients with malignant melanoma should be carried out to investigate occupational exposure as a possible risk factor. ${ }^{15}$ Occupational exposure factors such as fluorescent light $^{68}$ and soldering ${ }^{910}$ have been suggested but not confirmed.

In view of the small study and the low number of cases of malignant melanoma of the skin the interpretation of our findings is tentative. The occurrence of two new cases of malignant melanoma of the skin $\frac{7}{\mathbb{D}}$ however, in the extended follow up period seems to. strengthen the indicated causality between exposure to VCM and the development of malignant melanoma? of the skin in man.

We thank Patricia Flor for linguistic help and Anne Eide for typing the manuscript.

\section{References}

1 Storetvedt Heldaas S, Langård S, Andersen Aa. Incidence ő cancer among vinyl chloride and polyvinyl chloride workers? Br J Ind Med 1984;41:25-30.

2 Maltoni C, Lefemine G, Ciliberti A. Experimental research on vinyl chloride carcinogenesis. (Archives of Research in Indus ${ }^{2}$ trial Carcinogenicity, vol 2). Prinston Scientific Publishers, NJ 1984.

3 Salmon AG. Vinyl chloride: the evidence for human carcinot genicity in different target organs. $\mathrm{Br} J$ Ind Med 1985;42:73-4

4 Thomas TL, Decoufle P. Mortality among workers employed in the pharmaceutical industry. A preliminary investigation. $\mathcal{P}$ Occup Med 1979;21:619-23.

5 Alderson M, Rushton L. Mortality patterns in eight UK oid refineries. Ann NY Acad Sci 1982;381:139-45.

6 Beral V, Evans S, Shaw H, Milton G. Malignant melanoma and exposure to fluorescent light at work. Lancet 1982;ii:290-3.

7 Rigel DS, Fridman RJ, Levenstein MJ, Greenwald DT. Rela tionship of fluorescent lights to malignant melanoma: another view. J Dermatol Surg Oncol 1983;9:836-8.

8 Wright WE, Peters JM, Mack TM. Organic chemicals and malignant melanoma. Am J Ind Med 1983;4:577-81.

9 Vågerö D, Ahlbom A, Olin R, Sahlsten S. Cancer morbidity among workers in the telecommunications industry. $\mathrm{Br} J$ Ind Med 1985;42:191-5.

10 Sorahan R, Ashton RHR, Waterhouse JAH, Peters D, Roginski C. Malignant melanoma and occupations involving soldering IRS Med Sci Biochem 1985;13:830. 11 MacKie RM. Cutaneous malignant melanoma. $\mathrm{Br}$ Med $\underset{\text { 1983;287:1568-9. }}{\overrightarrow{\mathcal{F}^{2}}}$

12 Jönsson P-E, Olsson $\mathrm{H}$. Sun exposure and malignant melanoma Läkartidningen 1984;22:2249-52. (In Swedish.)

13 Magnus K. Habits of sun exposure and risk of malignant mela noma: an analysis of incidence rates in Norway 1955-1977 by cohort, sex, age, and primary tumor site. Cancer 1981, 48:2329-35.

14 Sober AJ, Fitzpatrick TB. Genetic and environmental factors oల malignant melanoma in man. Pigment Cell 1979;5:88-94.

15 Hilt B, Heldaas SS, Langård S. Can occupational exposure con-0 tribute to the development of malignant melanoma of the skin? Scand J Work Environ Health 1983;9:52-3. 